\title{
вмJ Global Health Making the world a simpler place: the modeller's temptation to seek alternative trial results
}

\author{
Tim Colbourn, ${ }^{1}$ Audrey Prost, ${ }^{2}$ Nadine Seward ${ }^{3}$
}

To cite: Colbourn T, Prost A, Seward N. Making the world a simpler place: the modeller's temptation to seek alternative trial results. BMJ Glob Health 2018;3:e001194. doi:10.1136/ bmjgh-2018-001194

Handling editor Seye Abimbola

Received 27 September 2018 Accepted 1 October 2018

\section{Sinked}

- http://dx.doi.org/10.1136/ bmjgh-2018-000808

Check for updates

C) Author(s) (or their employer(s)) 2018. Re-use permitted under CC BY-NC. No commercial re-use. See rights and permissions. Published by BMJ.

${ }^{1}$ UCL Institute for Global Health, London, UK

${ }^{2}$ Faculty of Public Health and Policy, London School of Hygiene and Tropical Medicine, London, UK

${ }^{3}$ Centre for Implementation Science, Department of Health Service and Population Research, King's College London, London, UK

Correspondence to Dr Tim Colbourn; t.colbourn@ucl.ac.uk
Murray et al suggest, via sophisticated mathematical modelling, that a radio intervention saved thousands of lives in Burkina Faso because it increased care-seeking for childhood illnesses, and that it could save tens of thousands more if scaled up across sub-Saharan Africa. ${ }^{2}$ In this commentary, we examine Murray et al's methods, remind readers that the Burkina Faso trial found no effect on child mortality and argue that privileging modelled over actual empirical data is both questionable and unnecessary.

We have five concerns about the methods used in Murray et al. First, the authors ignore empirically recorded mortality data from the trial's control arm, and instead choose to use a modelled estimate of higher mortality relative to the intervention arm. Second, the models assume that all children seeking treatment for pneumonia received appropriate care and oral antibiotics. We know this is often not the case and is even less likely when a health system is strained by sudden increases in careseeking. ${ }^{3}$ Third, there is no discussion of the significant increase in consultations for 'other diagnoses' in the trial's control arm. This indicates that the intervention significantly decreased consultations for 'other' diagnoses and calls into question the modelled mortality estimate. Fourth, the 'compression' methodused to account for multiple diagnoses in the same child and allow only one primary diagnosis-seems to favour malaria as the leading cause of death, which is responsible for much of the modelled mortality reduction. Finally, although the $5.5 \%$ modelled mortality reduction estimate for the third year has a negative lower bound $(95 \%$ CI $-0.1 \%$ to $13.1 \%)$, the authors report that the intervention saved between 239 and 1554 lives that year. ${ }^{1}$ These assumptions and possible errors together are likely to have inflated the estimated number of lives saved.

\section{Summary box}

Modelled results should not be prioritised over empirical trial results when these are available.

- Researchers need to consider theories of intervention effect, or lack of effect, and the roles of context when modelling results.

Increasing coverage of interventions may not lead to reductions in mortality.

Leaving these methodological concerns aside, Murray et al's work poses an interesting conundrum. Should modelled effects of an intervention on child mortality take precedence over actual, empirical mortality data from a randomised controlled trial (RCT)? Should every team with an underpowered trial now use secondary outcomes to model the effects of its interventions on distal health endpoints? The RCT found that the radio intervention's effect was compatible with the $7.1 \%$ reduction in under-5 mortality estimated through modelling, but also that its most likely effect on child mortality was... nothing (rate ratio: $1.00 ; 95 \%$ CI 0.82 to $1.22, \mathrm{p}>0.999){ }^{2}$ Null RCT results do not normally warrant calls for continent-wide scale-up. Surprisingly though, 21 news media outlets, including Reuters, BBC and $\mathrm{CNN}$, reported that thousands of lives have been saved through the radio intervention. ${ }^{45}$ Fortunately, the $\mathrm{BBC}$ Media Action Trust have since questioned the modellers' strong claims. ${ }^{6}$ The use of modelling methods on underpowered trials showing no evidence of effect on primary outcomes is a slippery slope. How many other interventions might this be done for, and when? When trials have an effect size of 1.00 (as here)? 1.10 perhaps?

There are many reasons why the trial may not have detected an effect on mortality, besides lack of power. ${ }^{7}$ Poor health system capacity and quality of care may mean that increased utilisation does not actually reduce 
deaths. The authors even note this possibility, but do not consider that increased utilisation itself could result in greater shortfalls as health facilities struggle to meet demand. ${ }^{8}$ Theoretically and practically, providing information and getting people to come to health facilities are only part of what is required. Reducing child mortality also requires strengthening health systems to meet demand in a timely, safe and equitable manner. To expect an effect on child mortality from radio messages alone is optimistic. To then create an effect via modelling when none was observed in a cluster RCT is puzzling. Going on-via the accompanying cost-effectiveness analysis ${ }^{9}$ to label the radio intervention 'the second most cost-effective intervention to save children's lives ever' is simply bizarre. ${ }^{8}$ The available resources to tackle important problems like child mortality are too small to spend on interventions that are unlikely to work, at least on their own. ${ }^{7}$

In a recent insightful commentary in this journal, Pai et al highlight that we are often surprised when interventions that lead to improvements in surrogate endpoints (eg, care-seeking) do not lead to lives being saved. ${ }^{10}$ For example, a recent RCT of the WHO Safe Childbirth Checklist in India found that birth attendants in facilities participating in the programme were more likely to adhere to safe practices, but no overall reductions in maternal and perinatal mortality. ${ }^{11}$ We should not be surprised. Like Rutter et $a l,{ }^{12}$ Pai and colleagues remind us that interventions are events that 'slot' into existing health and social systems and interact with them in complex ways. ${ }^{10}$ A safe birth checklist may help ensure critical tasks are done during childbirth, but it will not influence whether a pregnant woman reaches a facility on time, or whether a facility has drugs and equipment. The expectation that interventions which target discrete steps in the continuum of care-like radio messages or a checklist-can alone lead to reductions in mortality is likely unrealistic. Such reduction requires many steps occurring together. Incorporating a theory-based process evaluation ${ }^{13}$ or realist evaluation ${ }^{14}$ examining how the radio intervention's effects may have interacted with the health system and other contextual factors would have been useful to explain why the radio intervention alone was not able to reduce mortality. Such work would also enable us to understand the role mass media could play in more complete, real-world solutions to reduce child mortality. ${ }^{7}$

Pai et al encourage us to be both strategic and honest in our use of surrogate endpoints ${ }^{10}$ : some interventions (like the radio messages) are specifically developed to influence them. Moreover, health systems factors will always influence pathways to more distal health outcomes. Celebrating the increase in care-seeking and acknowledging that, in the context of the Burkina trial, no mortality reduction is more plausible than thousands of lives saved is a good step towards honesty.

Contributors TC wrote the first draft of the commentary which was improved by AP and NS. All authors reviewed and agreed with the final version.

Competing interests None declared.

Patient consent Not required.

Provenance and peer review Commissioned; internally peer reviewed.

Data sharing statement № additional data are available.

Open access This is an open access article distributed in accordance with the Creative Commons Attribution Non Commercial (CC BY-NC 4.0) license, which permits others to distribute, remix, adapt, build upon this work non-commercially, and license their derivative works on different terms, provided the original work is properly cited, appropriate credit is given, any changes made indicated, and the use is non-commercial. See: http://creativecommons.org/licenses/by-nc/4.0

\section{REFERENCES}

1. Murray J, Head R, Sarrassat S, et al. Modelling the effect of a mass radio campaign on child mortality using facility utilisation data and the Lives Saved Tool (LiST): findings from a cluster randomised trial in Burkina Faso. BMJ Glob Health 2018;3:e000808.

2. Sarrassat $\mathrm{S}$, Meda $\mathrm{N}$, Badolo $\mathrm{H}$, et al. Effect of a mass radio campaign on family behaviours and child survival in Burkina Faso: a repeated cross-sectional, cluster-randomised trial. Lancet Glob Health 2018;6:e330-e341.

3. Mosites EM, Matheson Al, Kern E, et al. Care-seeking and appropriate treatment for childhood acute respiratory illness: an analysis of Demographic and Health Survey and Multiple Indicators Cluster Survey datasets for high-mortality countries. BMC Public Health 2014;14:446.

4. Mundasad S. The radio 'saved my little girl's life' (BBC News). 2018. Available from: https://http://www.bbc.co.uk/news/health-45133298 [accessed 18 Aug 2018].

5. Smith R. Simple radio message saved thousands of children, studies say. 2018. Available from: https://edition.cnn.com/2018/07/18/ health/mass-radio-health-burkina-faso-intl/ [accessed 19 Aug 2018].

6. Deane J. Health effects of mass-media interventions. Lancet Glob Health 2018;6:e960.

7. Colbourn T, Prost A. Making waves: can radio reduce child mortality? Lancet Glob Health 2018;6:e238-e239.

8. Hurst TE, Semrau K, Patna M, et al. Demand-side interventions for maternal care: evidence of more use, not better outcomes. BMC Pregnancy Childbirth 2015;15:297.

9. Kasteng F, Murray J, Cousens S, et al. Cost-effectiveness and economies of scale of a mass radio campaign to promote household life-saving practices in Burkina Faso. BMJ Glob Health 2018;3:e000809.

10. Pai M, Schumacher SG, Abimbola S. Surrogate endpoints in global health research: still searching for killer apps and silver bullets? BMJ Glob Health 2018;3:e000755.

11. Semrau KEA, Hirschhorn LR, Marx Delaney M, et al. Outcomes of a coaching-based WHO safe childbirth checklist program in India. N Engl J Med 2017;377:2313-24.

12. Rutter H, Savona N, Glonti K, et al. The need for a complex systems model of evidence for public health. Lancet 2017;390:2602-4.

13. Moore GF, Audrey S, Barker M, et al. Process evaluation of complex interventions: Medical Research Council guidance. BMJ 2015;350:h1258.

14. Bonell C, Moore G, Warren E, et al. Are randomised controlled trials positivist? Reviewing the social science and philosophy literature to assess positivist tendencies of trials of social interventions in public health and health services. Trials 2018;19:238. 